\title{
Mechanical properties and environmental stress cracking resistance of rubber toughened polyester/kenaf composite
}

\author{
N. N. Bonnia ${ }^{*}$, S. H. Ahmad ${ }^{2}$ I. Zainol ${ }^{3}$, A. A. Mamun 4 , M. D. H. Beg5, A. K. Bledzki ${ }^{4}$ \\ ${ }^{1}$ Material Technology Department, Faculty of Applied Sciences, Universiti Teknologi Mara (UiTM), 40450 Shah Alam, \\ Selangor, Malaysia \\ ${ }^{2}$ Department of Material Science, Faculty of Applied Physics, Universiti Kebangsaan Malaysia, 43600 Bangi, Selangor, \\ Malaysia \\ ${ }^{3}$ Chemistry Department, Faculty of Science and Technology, Universiti Sultan Idris 35900 Tanjung Malim, Perak, \\ Malaysia \\ ${ }^{4}$ Institute of Material Engineering, University of Kassel, Moncheberg str. 3, 34125 Kassel, Germany \\ ${ }^{5}$ Faculty of Chemical and Natural Resources Engineering, Universiti Malaysia Pahang, Kuantan, Malaysia
}

Received 10 June 2009; accepted in revised form 29 October 2009

\begin{abstract}
In this study rubber-toughened polyester-kenaf fibre composites were prepared by adding various percentages of kenaf fibre in unsaturated polyester resin and subsequently cross linked using a mixture of organic peroxide methyl ethyl ketone and cobalt octanoate. Three percent (3\%) of liquid natural rubber (LNR) were added as a toughening agent. The mechanical properties of the composites were evaluated by impact and flexural testing. Environmental stress cracking resistance (ESCR) of polyester-kenaf composite in acid and base medium was also studied. It was found that the addition of LNR increased impact strength by about $66 \%$ and flexural strength by $70 \%$. Measurement of ESCR shows that the composite has the fastest diffusion rate in acid medium, followed by that in base medium and then without medium. Bonding mechanisms were assessed by scanning electron microscope and FTIR analysis.
\end{abstract}

Keywords: polymer composites, polyester, toughened, liquid natural rubber (LNR), kenaf

\section{Introduction}

In recent decades, growing environmental awareness has resulted in renewed interest in the use of natural materials for various applications. Increasingly more stringent environmental policies have forced industries such as the automotive, packaging and construction industries to search for new materials that can substitute traditional composite materials consisting of a plastic matrix and inorganic reinforcement [1]. The availability of bio-based structural composites offer the opportunity for environmental gains, reduced consumption of more expensive materials, lighter weight, improved insulation and sound absorption properties, and reduc- tion in dependence on petroleum-based and forest product materials. The production of synthetic fibres, such as glass, aramid and carbon fibres, are energy-intensive and are petroleum based. Kenaf, Hibiscus cannabinus L. fiber is obtained from renewable resources, which is biodegradable, environmentally friendly and offer $\mathrm{CO}_{2}$ neutral life cycle [2]. The most rapidly expanding application for kenaf at present is as reinforcement in composites. The matrix materials popularly used in kenaf fibre composites ranges from thermoplastics, such as polypropylene and polyethylene, to thermosets, such as polyester, epoxy [3-5]. 
Unsaturated polyester resins are the most frequently used thermosetting system owing to their low cost and adaptability to be transformed into large composite structures. The most frequently used reinforcement in this system is provided by sized glass fibres available as fabrics of various orientation, shapes and densities. More recently, the possibility of using cellulosic fibres as reinforcement in composites has yielded several studies. For instance, Dash et al. [6] reported the mechanical properties of jute fibre/unsaturated polyester composites. The authors optimised the fibre loading (60 $\mathrm{wt} \%)$ that has the maximum tensile strength of $132 \mathrm{MPa}$ and Young's modulus 2.9 GPa for composites. Acha et al. [7] used jute fabric to reinforce unsaturated polyester resin. The results showed that the Young's modulus of all the composites increased significantly (fibre content 46 to $56 \mathrm{wt} \%$ ) tensile strength of the composite was, however, not improved.

Although polyester resins are widely used as a matrix in polymer composites, curing of these resins results in brittleness due to their high crosslinking level. The addition of a low molecular weight reactive liquid rubber can improve fracture toughness and impact strength of the cured polyester resin. The purpose of introducing dispersed rubber particles into the primary phase in these systems is to enhance their toughness. It is known that both rubber particle size and volume fraction affect the degree to which the polyester is toughened [8]. Dahlan et al. [9] has extensively studied the utilization of liquid natural rubber (LNR) as a compatibilizer on various natural rubber/polyolefin blends. They found that the LNR has the same microstructure as NR but with short chains of polyisoprene and a different in molecular weight $\left(M_{w}\right)$. The $M_{w}$ for LNR is around 5000 whereas for NR it is 900 000. The LNR with some active terminals like $-\mathrm{OH}$ is expected to react with the plastic particles and thereby bond the plastic particles to the NR matrix. Studies on NR and various PE with LNR as a compatibilizer have successfully shown that LNR can act as plasticizer or cross linking agent, depending on its molecular weight $[9,10]$. Therefore, this study investigates the effects of the addition of liquid natural rubber (LNR) and kenaf to a polyester matrix on the mechanical properties of the composites.

\section{Material and methods \\ 2.1. Preparation of fibres}

The kenaf fibres used had been harvested at 4 months of age. Fibres were then cut and ground with an Ika Werke MF10 heavy duty grinder (Staufen, Germany) and finally sieved into 300500 micron sizes. The kenaf fibre diameter was 20-55 $\mu \mathrm{m}$.

\subsection{Preparation of the matrix}

LNR is prepared according to a method described by Abdullah and Ahmad [11]. The $M_{w}$ for LNR is about 5000. Unsaturated polyester Reversol UN 8100 P-8542CSH from Revertex Sdn. Bhd., Malaysia was used in this research. For the composites without LNR, the polyester resin was mixed with the initiator methyl ethyl ketone peroxide (MEKP) and cobalt octanoate 1\%. For the composite with LNR, the polyester resin and the LNR were stirred for 30 minutes before mixing with the initiator.

\subsection{Preparation of composites board}

Dried kenaf fibres were measured into 5, 10, 15, 20 and $25 \%$ (by weight) and mixed with polyester resin and LNR. The mixture was put into the mould and pressed at $70 \mathrm{MPa}$ pressure at $90^{\circ} \mathrm{C}$ for $15 \mathrm{~min}$ utes. Aziz et al. reported that the curing of polyester at different temperatures with different durations ensures full cure and provides better performance [12]. The resulting board was cured at room temperature for 24 hours and post cured successively at $60^{\circ} \mathrm{C}$ for 2 hours, $90^{\circ} \mathrm{C}$ for 90 minutes, $120^{\circ} \mathrm{C}$ for 1 hour and $150^{\circ} \mathrm{C}$ for 30 minutes. The mechanical properties of each type of board were then evaluated after cutting the samples to the required shape for different test. PK is abbreviation for polyester kenaf composites, PKL is abbreviation for polyester kenaf composites with LNR.

\subsection{Composite characterization}

Flexural strength was measured under a three-point bending approach using a Universal Testing machine (Testometric 350, UK) according to ASTM D 790-91. The dimensions of the samples were $120 \mathrm{~mm} \times 20 \mathrm{~mm} \times 3 \mathrm{~mm}$. The distance between 
the spans was $100 \mathrm{~mm}$, and the test speed was $5 \mathrm{~mm} / \mathrm{min}$. Impact testing was carried out with a Ray Ran Pendulum Impact System (Warwickshire, UK) according to ASTM D 256. Fracture toughness was determined according to ASTM E 399 using a three-point bending flexural test. The test speed was $2 \mathrm{~mm} / \mathrm{min}$. For mechanical testing 5 specimens were tested for each batch to get the average values.

Environmental stress cracking resistance (ESCR) tests were carried out using a Universal Testing machine (Zwick 1440, Germany) according to ISO standard 22088-3:2006. Samples were prepared with dimensions of $80 \mathrm{~mm} \times 4 \mathrm{~mm} \times 10 \mathrm{~mm}$. The specimen was bent using a three-point bending jig mounted in a chemical environment chamber. The test was undertaken in control medium (Air), $1 \%$ sodium hydroxide $(\mathrm{pH} 13.5)$ and $1 \%$ hydrochloride acid ( $\mathrm{pH} 2.5$ ) medium. Three conditions of the environment were used in this test:

- Without medium (om)

- With acid medium (am)

- With base medium (bm)

After $t_{0}$, defined as the time necessary to stabilize the loading condition, the chemical was rapidly introduced into the chamber under stress. The variation of the stress was recorded using a sensitive load cell $100 \mathrm{~N}$ connected to multimeter incrementally at $t_{0}=120 \mathrm{~s}, t_{1}=120 \mathrm{~s}, t_{2}=180 \mathrm{~s}, t_{3}=180 \mathrm{~s}$, $t_{4}=300 \mathrm{~s}, t_{5}=300 \mathrm{~s}, t_{6}=300 \mathrm{~s}$. When the stressed composite is exposed to a chemical environmental, polymer resistance will vary with time. Since micro crazes, crazes or cracks weaken the chemically exposed polymer, it will tend to have both a shorter time to rupture and a lower stress value in comparison with the control specimen (without medium). The test was carried out under laboratory conditions in an air conditioned room, controlled at $23 \pm^{\circ} \mathrm{C}$ and $50 \%$ relative humidity. The $E$ factor was calculated as the stress in control medium divided by the stress in corrosive medium at a certain time. Morphological observation of the flexural fracture surface of the composite with different compositions was done by a scanning electron microscope (Philips XL 30 ESEM). FTIR spectrum of samples was recorded using FTIR (Perkin Elmer 500, Nicolet 6000 , UK) spectroscopy from 4000 to $400 \mathrm{~cm}^{-1}$ using $\mathrm{KBr}$ disk. $20 \%$ kenaf fibre composites were chosen for SEM and FTIR experiment.

\section{Results and discussion \\ 3.1. Impact properties}

The impact strength of matrix and composites are presented in Figure 1. It can be seen that the impact strength of the matrix was higher than that of the composites with lower fibre content, then the impact strength increased in general with increasing fibre loading. The lower value of impact strength at lower fibre content could be due to the introduction of flaws created by the fibre ends. These flaws act as stress concentrations, and cause the bond between fibre and matrix to break. At higher volume fractions, the matrix is sufficiently restrained and the stress is more evenly distributed. This results in reinforcing effects outweighing the effects of the stress concentrations and results in increase of impact strength at higher fibre loading [13]. Although, benefit was seen in higher fibre loading, however, the fibre loading was limited to $25 \mathrm{wt} \%$ due to limited wettability of the resin; and higher than $25 \mathrm{wt} \%$ (for example $30 \mathrm{wt} \%$ ) the polyester resin could not wet the fiber sufficiently and could not penetrate into the fiber mass. The impact test is a standardized high strain-rate test which determines the amount of energy absorbed by a material during fracture. This absorbed energy is a measure of a given material's toughness and acts as a tool to study brittle-ductile transition. The impact strength of composites may also be influenced by many other factors including the toughness of the reinforcement, the nature of the interfacial region, and the frictional work involved in pulling the fibres from the matrix $[14,15]$. Addition of liquid natural rubber (LNR) was found to improve the impact properties of composites by 35 to $125 \%$, probably due to the presence of rubber particles in the polyester which may have acted as impact modifier in the composite. The highest impact strength

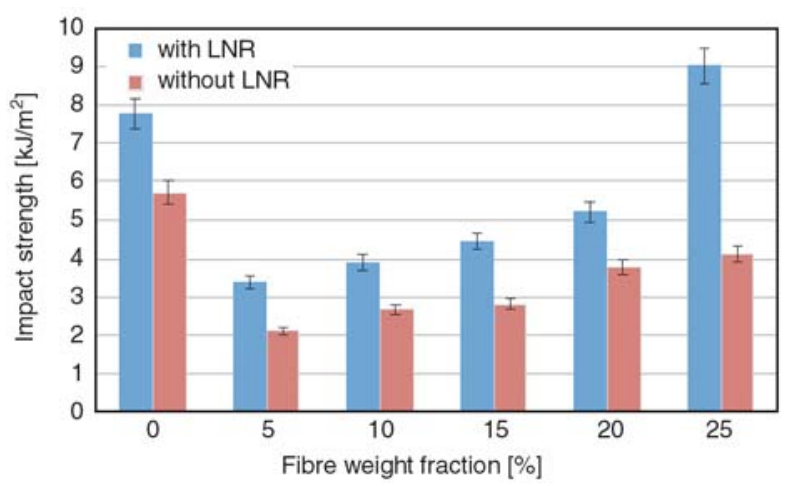

Figure 1. Impact properties of polyester/kenaf composites 
was found for $25 \%$ fibre loading composites with LNR which was about $125 \%$ higher than that of compositions without LNR. It may be the reason that the fibre loading was reached the critical fibre load for this system in which fibres were distributed evenly and absorbed more energy.

\subsection{Flexural strength of composite}

Figures 2 and 3 present the effects of fibre loading and addition of liquid natural rubber (LNR) on the flexural properties of the polyester kenaf composites. Both flexural strength and modulus were found to be higher than that of composites containing lower amount of fibre loading, however, both flexural strength and modulus were found to be increased significantly as the fibre volume fraction increased. As discussed earlier, at lower fibre content, below critical fibre volume fraction, fibre ends act as stress concentrations, and cause the bond between fibre and matrix to break. At higher volume fractions, the matrix is sufficiently restrained and the stress is more evenly distributed. This results in reinforcing effects outweighing the effects of the stress concentrations and results in increase in flexural strength and modulus $[13,16]$. Although, the flexural behavior of composites without LNR tended to behave like composite with LNR, however, generally a slight reduction of

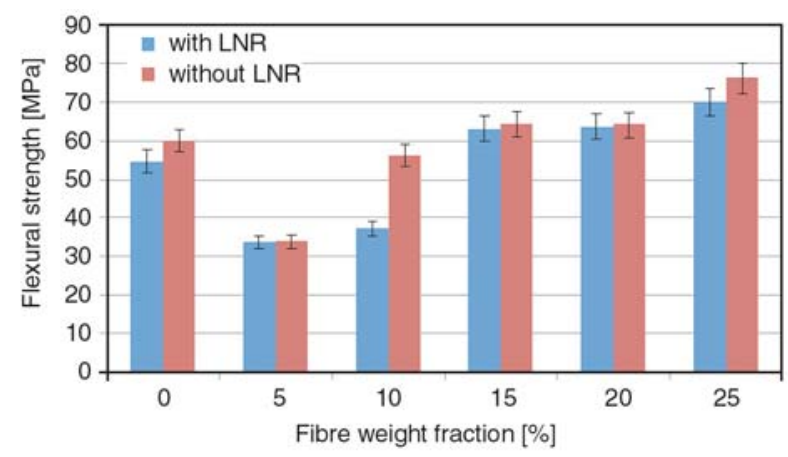

Figure 2. Flexural strength of polyester/kenaf composites

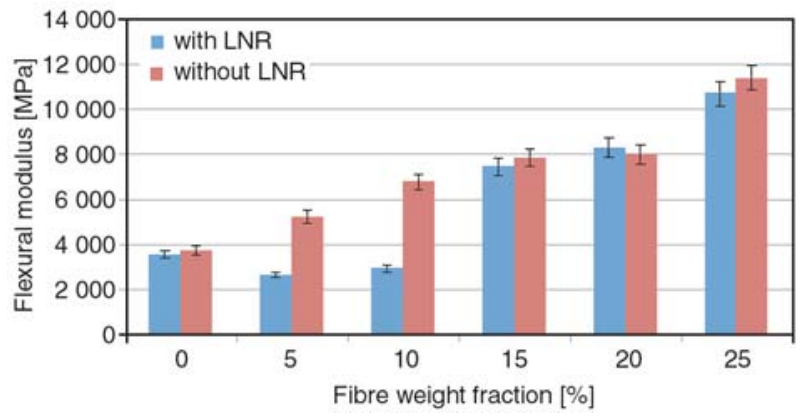

Figure 3. Flexural modulus of polyester/kenaf composites strength and modulus were found for composites with LNR. This reduction of flexural properties could be due to the plasticizing effect of rubber particle which increased flexibility and reduced toughness.

\subsection{Fracture toughness of composite}

The crack growth behaviors of composite are compared in Figure 4 based on $K_{i c}$ values. Fracture toughness of composites both with and without LNR were increased with increasing fibre volume, however, the values dropped after $15 \%$ of fibre loading for composites without LNR and $20 \%$ fibre loading for composites with LNR. The reduction of $K_{i c}$ at higher fibre content composites may be due to increased fibre-fibre contacts which would make it comparatively easier for the fibre to debond from the resin than for composites at lower fibre fraction composites. Therefore, larger force could be required for the fibre to be debonded from the matrix at lower fibre content. The addition of higher percentages of kenaf also could interfere with the cross linking process and decrease the $K_{i c}$ values $[3,17]$. It was also noted that the fracture toughness values were higher for composites with LNR which could be due to the plasticizing effect of rubber particle which increased flexibility and needed more force to debonding.

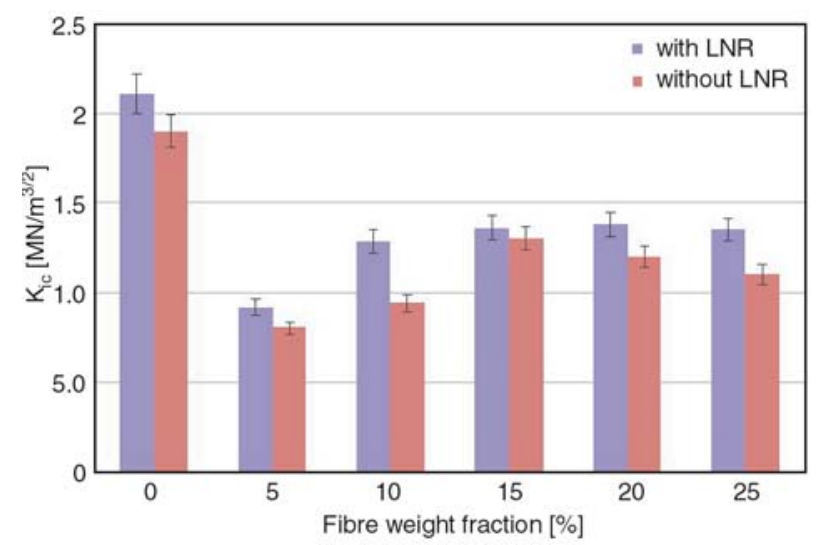

Figure 4. Fracture toughness of composites

\subsection{Environmental stress cracking resistance (ESCR)}

Environmental stress cracking resistance is the premature initiation of cracking and embrittlement of a plastic due to the simultaneous action of stress and strain in contact with a specific fluid. This phenom- 


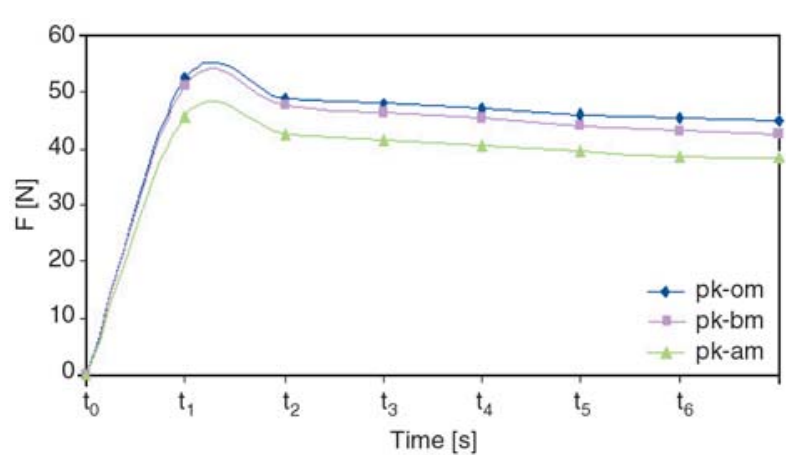

Figure 5. Comparison on ESCR effect of the kenaf composites

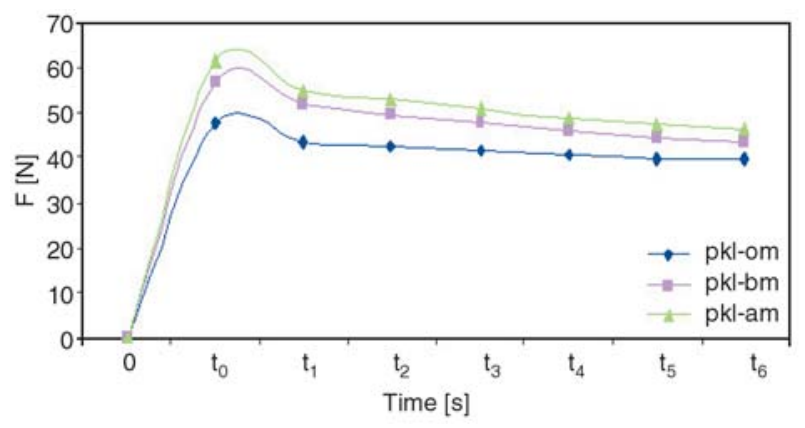

Figure 6. Comparison on ESCR effect of the kenaf composites toughened LNR

enon is also described as environmentally assisted cracking [18]. Figures 5 and 6 show that stress values rapidly decreased, whether the composites had acid or base medium. The stress values of composites without medium declined over time but the reduction was found to be less than that of composites with medium. Both composites, without LNR and with LNR showed the same trend across the three different medium conditions. However, acid medium weakened the composite more rapidly than the base medium. Figure 5 indicates that over time, polyester composite with LNR decreased the stress by $25 \%$ with acid medium and $23 \%$ with base medium. Figure 6, however, shows that the stress value of polyester composite without LNR decreased $16 \%$ on acid medium and $20 \%$ on base medium. The stress value of composites LNR declined about $17 \%$ with control medium whiles those composites without LNR declined by about $14 \%$. Figures 5 and 6 reveals that when the stressed composite is exposed to a chemical environment, the polymer resistance to acid and base varies with time. Since micro crazes, crazes or cracks weaken the polymer exposed to chemicals, it will tend to have both a shorter time to rupture and a lower stress value, compared to those of a control specimen without medium. It can also be noted that composites without LNR are more resistant in different chemical environment which could be due to rubber particle may debonded or degraded out from composites more easily than the resin.

\subsection{Infrared spectroscopy}

A series of Fourier transform infra red (FTIR) spectra were obtained to detect any chemical interaction between polyester-kenaf composites and polyesterkenaf with LNR composites. The FTIR spectra of cured polyester- kenaf composites and polyesterkenaf with LNR composites are shown in Figure 7. A new peak was observed on FTIR spectrum of modified polyester as compared to unmodified polyester. An aromatic functional group $(\mathrm{C}-\mathrm{C}$ stretch in ring) was observed from the absorption band 1600 and $1475 \mathrm{~cm}^{-1}$ and an alkanes group $\left(\mathrm{CH}_{3}\right)$ from the absorption band $1376 \mathrm{~cm} \mathrm{~cm}^{-1}$ for composites with LNR [19]. It can be note that the aromatic functional group can also appear from matrix polymer. A hydroxyl group was observed for both peaks from the absorption band 3600$3300 \mathrm{~cm}^{-1}$. It was identified with existing stretching band on $1300-1000 \mathrm{~cm}^{-1}(\mathrm{C}-\mathrm{O})$. The carbonyl region $\left(1800-1600 \mathrm{~cm}^{-1}\right)$ reveals probably the presence of carbonyl group from the isoprene chain of liquid natural rubber. Carbonyl absorption was observed in both spectra but with different intensity.

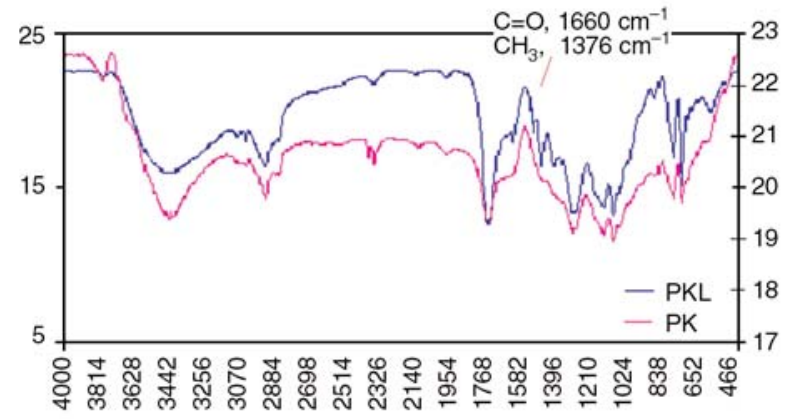

Figure 7. Infrared spectroscopy of the composites

\subsection{Morphological analysis}

Figure 8 shows the flexural fracture surface of composites. Good bonding was evident from both type composites with and without LNR. Fibre fracture can be seen and there is absence of hole and fibre pullout. However, for composites without LNR, it can be seen a gap between fibre and 


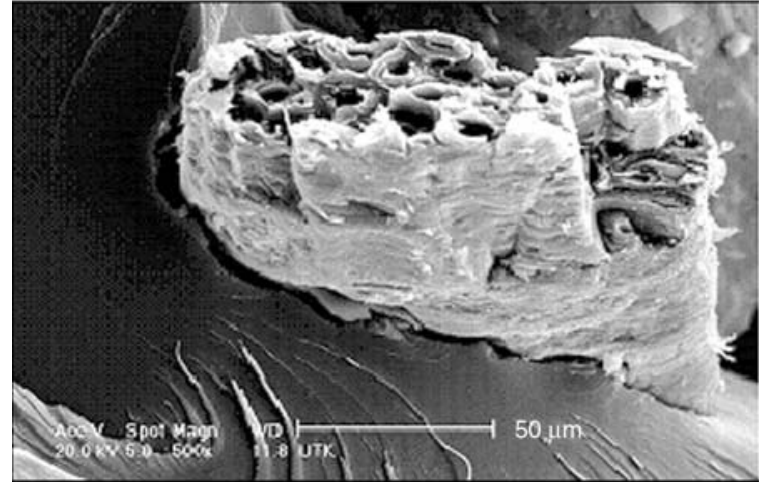

(a1)

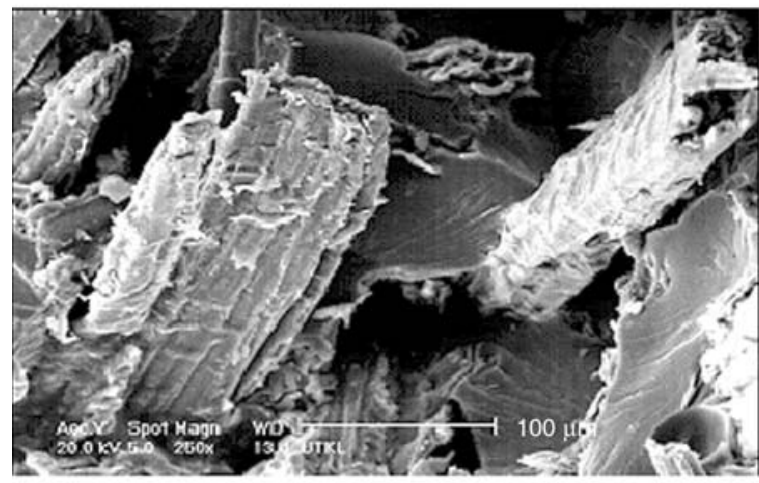

(b1)

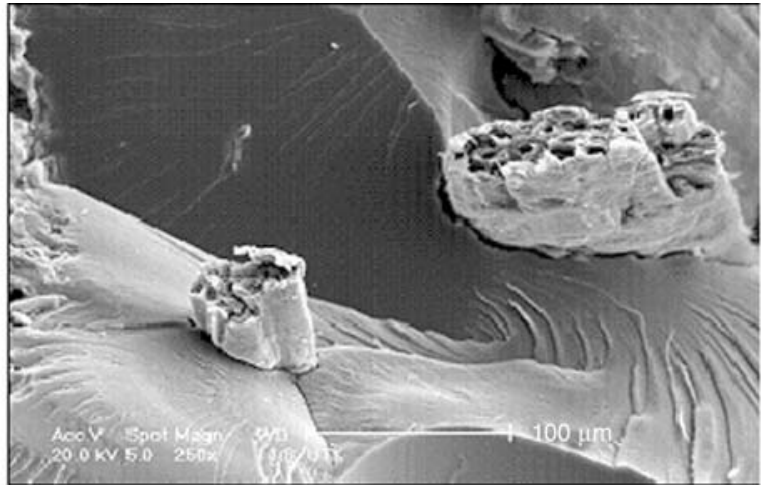

(a2)

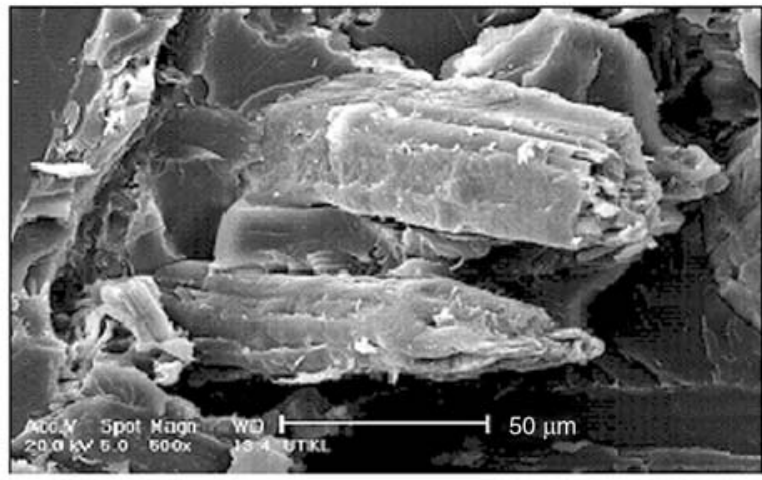

(b2)

Figure 8. SEM micrograph of composites at $250 \times$ and $500 \times$ magnifications: (a) polyester-kenaf composites, (b) polyester-kenaf with LNR composites

embedded resin (Figures 8a1 and 8a2). It is well known that unsaturated polyester networks shrink considerably after curing. This shrinkage reduces the specific volume of the matrix, and it results in free spaces between the matrix and the fibre. On the other hand, for composites with LNR the region surrounding the cellulosic filler seems to be continuous with the matrix phase (Figures $8 b 1$ and $8 b 2$ ).

\section{Conclusions}

1. The result shows that liquid natural rubber is a good potential toughening agent for polyester resin.

2. Impact, flexural and fracture toughness properties were found be improved significantly with increasing fibre volume faction, however, optimum mechanical properties were found be around $20 \%$ fibre loading.

3. Fracture toughness and impact strength of polyester kenaf composite noticeably increased with the addition of a small amount of liquid natural rubber in composites.
4. Environmental stress cracking resistance shows that the composites are more affected on acid medium followed by base medium.

\section{Acknowledgements}

The authors acknowledge financial support for this research work from: the Malaysian Ministry of Science and Technology (MOSTI) under ScienceFund 03-01-02-SF01223; Universiti Kebangsaan Malaysia, Bangi, Malaysia; SIRIM Bhd, Shah Alam, Malaysia; Universiti Technology Mara, Shah Alam, Malaysia; and the Institute of Material Engineering, Sophie Henschel Haus, Plastic and Recycling Engineering, Kassel University, Kassel, Germany.

\section{References}

[1] Espert A., Vilaplana F., Karlsson S.: Comparison of water absorption in natural cellulosic fibres from wood and one-year crops in polypropylene composites and its influence on their mechanical properties. Composites Part A: Applied Science and Manufacturing, 35, 1267-1276 (2004).

DOI: $10.1016 /$ j.compositesa.2004.04.004 
[2] Annuar H., Ahmad S. H., Rasid R., Ahmad A., Wan Busu W. N.: Mechanical properties and dynamic mechanical analysis of thermoplastic-natural-rubberreinforced short carbon fibre and kenaf fibre hybrid composites. Journal of Applied Polymer Science, 107, 4043-4052 (2007).

DOI: 10.1002/app.27441

[3] Aziz S. H., Ansell M. P.: The effect of alkalization and fibre alignment on the mechanical and thermal properties of kenaf and hemp bast fibre composites: Part 1 polyester resin matrix. Composites Science and Technology 64, 1219-1230 (2009).

DOI: 10.1016/j.compscitech.2003.10.001

[4] Bledzki A. K., Mamun A. A., Faruk O.: Abaca fibre reinforced PP composites and comparison with jute and flax fibre PP composites. Express Polymer Letters, 1, 755-762 (2007).

DOI: 10.3144/expresspolymlett.2007.104

[5] Kafi A. A., Abedin M. Z., Beg M. D. H., Pickering K. L., Khan M. A.: Study on the mechanical properties of jute/glass fiber-reinforced unsaturated polyester hybrid composites: Effect of surface modification by ultraviolet radiation. Journal of Reinforced Plastics and Composites, 25, 575-588 (2006).

DOI: $10.1177 / 0731684405056437$

[6] Dash B. N., Rana A. K., Mishra H. K., Nayak S. K., Mishra S. C., Tripathy S. S.: Novel, low-cost jutepolyester composites. Part 1: Processing, mechanical properties, and SEM analysis. Polymer Composites, 20, 62-71 (2006).

DOI: $10.1002 /$ pc.10335

[7] Acha B. A., Marcovich N. E., Reboredo M. M.: Physical and mechanical characterization of jute fabric composites. Journal of Applied Polymer Science, 98, 639-650 (2005). DOI: $10.1002 / a p p .22083$

[8] Zainol I., Ahmad I. B., Zakaria F. A., Ramli A., Marzuki H. F. A., Aziz A. A.: Modification of epoxy resin using liquid natural rubber. Materials Science Forum, 517, 272-274 (2006). DOI: $10.4028 /$ www.scientific.net/MSF.517.272

[9] Dahlan H. M., Khairul Zaman M. D., Ibrahim A.: Liquid natural rubber (LNR) as a compatibiliser in NR/LLDPE blends II: The effects of electron-beam (EB) irradiation. Radiation Physics and Chemistry, 64, 429-436 (2002). DOI: $10.1016 / \mathrm{S} 0969-806 \mathrm{X}(01) 00491-1$
[10] Ibrahim A., Dahlan H. M.: Thermoplastics natural rubber blends. Progress in Polymer Science, 23, 665-706 (1998). DOI: $10.1016 / \mathrm{S} 0079-6700(97) 00052-\mathrm{X}$

[11] Abdullah I., Ahmad S.: Liquid natural rubber as a compatibilizer in the blending of natural rubber with polypropylene. Material Forum, 16, 353-357 (1992).

[12] Aziz S. H., Ansell M. P.: The effect of alkalizations and fibre alignment on the mechanical and thermal properties of kenaf and hemp bast fibre composites: Part 2 - Cashew nut shell liquid matrix. Composites Science and Technology, 64, 1231-1238 (2004). DOI: 10.1016/j.compscitech.2003.10.002

[13] Bibo G. A., Hogg P. J.: The role of reinforcement architecture on impact damage mechanisms and postimpact compression behaviour. Journal of Materials Science, 31, 1115-1137 (1996). DOI: $\underline{10.1007 / \mathrm{BF} 00353091}$

[14] Bledzki A. K., Gassan J.: Composites reinforced with cellulose based fibres. Progress in Polymer Science, 24, 221-274 (1999). DOI: $10.1016 / \mathrm{S} 0079-6700(98) 00018-5$

[15] Bledzki A. K., Mamun A. A., Lucka-Gabor M., Gutowski V. S.: The effects of acetylation on properties of flax fibre and its polypropylene composites. Express Polymer Letters, 2, 413-422 (2008). DOI: $10.3144 /$ expresspolymlett.2008.50

[16] Sreekala M. S., Jayamol G., Kumaran M. G., Sabu T.: The mechanical perfomance of hybrid phenolformaldehyde based composites reinforced with glass and oil palm fibres. Composites Science and Technology, 62, 339-353 (2002). DOI: $10.1016 / \mathrm{S} 0266-3538(01) 00219-6$

[17] Ismail H., Shuhelmy H., Edyham M. R.: The effects of a silane coupling agent on curing characteristics and mechanical properties of bamboo fibre filled natural rubber composites. European Polymer Journal, 38, 39-47 (2002).

DOI: $\underline{10.1016 / \mathrm{S} 0014-3057(01) 00113-6}$

[18] Wright D. R.: Environmental stress cracking of plastic. Rapra Technology, Shawbury (1996).

[19] Stuart B.: Biological applications of infrared spectroscopy. Wiley, New York (1997). 